\title{
Association of MDM2 SNP309 and TP53 Arg72Pro polymorphisms with risk of endometrial cancer
}

\author{
TOMOKO YONEDA ${ }^{1}$, AYUMI KUBOYAMA ${ }^{1}$, KIYOKO KATO ${ }^{1}$, TATSUHIRO OHGAMI ${ }^{1}$, \\ KANAKO OKAMOTO $^{1}$, TOSHIAKI SAITO ${ }^{2}$ and NORIO WAKE $^{1}$ \\ ${ }^{1}$ Department of Obstetrics and Gynecology, School of Medicine, Kyushu University, Fukuoka 812-8582; \\ ${ }^{2}$ Gynecology Service, National Kyushu Cancer Center, Fukuoka 811-1395, Japan
}

Received January 18, 2013; Accepted March 28, 2013

DOI: $10.3892 /$ or.2013.2433

\begin{abstract}
The incidence of endometrial cancer, a common gynecological malignancy, is increasing in Japan. We have previously shown that the ER/MDM2/p53/p21 pathway plays an important role in endometrial carcinogenesis. In the present study, we investigated the effects of germline single nucleotide polymorphisms in murine double minute 2 (MDM2) SNP309, TP53 Arg72Pro, ESRl PvuII and XbaI, and $p 21$ codon 31 on endometrial cancer risk. We evaluated these polymorphisms in DNA samples from 125 endometrial cancer cases and 200 controls using polymerase chain reaction-based restriction fragment length polymorphism. The association of each genetic polymorphism with endometrial cancer was examined by the odds ratio and $95 \%$ confidence interval, which were obtained using logistic regression analysis. The SNP309 GG genotype non-significantly increased the risk of endometrial cancer. The 95\% confidence interval for the GG genotype vs. the TT genotype of MDM2 SNP309 was 1.76 (0.93-3.30). Endometrial cancer was not associated with tested SNP genotypes for TP53, ESR1 and $p 21$. The combination of SNP309 GG + TG and TP53 codon 72 Arg/Arg significantly increased endometrial cancer risk. The adjusted OR was 2.53 (95\% confidence interval, 1.03-6.21) and P for the interaction was 0.04 . This result was supported by in vitro data showing that endometrial cancer cell lines with the SNP309 G allele failed to show growth inhibition by treatment with RITA, which reduces p53-MDM2 binding. The presence of the SNP309 G allele and TP53 codon $72 \mathrm{Arg} / \mathrm{Arg}$ genotype is associated with an increased risk of endometrial cancer in Japanese women.
\end{abstract}

\section{Introduction}

The incidence of endometrial cancer is increasing; it is the second most common gynecologic malignancy in Japan.

Correspondence to: Professor Kiyoko Kato, Department of Obstetrics and Gynecology, School of Medicine Kyushu University, Maidashi 3-1-1, Higashi-ku, Fukuoka 812-8582, Japan

E-mail: kkato@med.kyushu-u.ac.jp

Key words: MDM2 SNP309, TP53 Arg72Pro, ESR1 PvuII XbaI, p21 codon 31, endometrial cancer
Increased estrogen exposure, particularly unopposed estrogen, is a major risk factor for endometrial cancer. Early menarche, infertility, obesity and late menopause are also associated with increased risk of the cancer. Endometrial cancer is broadly classified into one of two clinicopathological types: I and II (1). The former is estrogen-related and occurs in both premenopausal and postmenopausal women. Histologically, it is of the endometrioid type, generally of low cellular grade and has a favorable prognosis. It is frequently preceded by endometrial hyperplasia. These tumor cells frequently express the estrogen receptor (ER), particularly ER $\alpha$. Type I endometrial cancer development is associated with a variety of genetic alterations, including PTEN inactivation, K-ras mutation, $\beta$-catenin mutation and microsatellite instability. Type II endometrial cancer is non-estrogen-related and occurs primarily in postmenopausal women. Type II encompasses non-endometrioid histologies and is represented by serous or clear-cell adenocarcinoma. It is commonly associated with an atrophic rather than a hyperplastic endometrium. The cells are negative for ER and the progesterone receptor (PR); type II endometrial cancer exhibits a high cellular grade and is associated with poor prognosis. Genetic alterations in type II carcinomas include p53 mutation, p16 inactivation, HER-2/neu overexpression and reduced E-cadherin expression $(1,2$.)

A human homologue of the murine double minute 2 (MDM2) gene (also known as HDM2 in humans) is frequently overexpressed in several types of human cancer, particularly in breast carcinomas and soft tissue sarcomas (3). The major contribution of MDM2 to cancer development is through tight inhibition of tumor suppressor p53 activity and stability. Biochemically, MDM2 functions as an E3 ubiquitin ligase responsible for p53 ubiquitination and degradation (4-6). Recent studies have identified numerous additional MDM2interacting proteins and p53-independent functions of MDM2 in the regulation of multiple signaling pathways, including the $\mathrm{pRb} / \mathrm{E} 2 \mathrm{~F}$ complex and the PI3K/Akt pathway (7). MDM2 overexpression is also strongly related to the presence of ER $(8,9$.$) Elevated ER expression in cells lacking ER induces$ MDM2 overexpression (3). We have shown that overexpression of wild-type ER $\alpha$ in NIH3T3 cells results in a significant increase in MDM2 protein levels. MDM2 gene expression is also regulated by the Ras-driven Raf/MEK/MAP kinase pathway in a p53-independent manner (10). We have also 
demonstrated that the Ras/ER/MDM2 pathway is critical for NIH3T3 cell transformation $(11,12)$ and that blockage of this pathway by inhibitors or MDM2 siRNA induces p53 and p21 expression and suppresses cell proliferation in estrogendependent cancer such as endometrial and ovarian cancer (13). These results suggest that the ER/MDM2/p53/p21 pathway plays an important role in the development of endometrial cancer.

A single nucleotide polymorphism (SNP309 $\mathrm{T}>\mathrm{G}$; rs2279744) has been identified in the MDM2 promoter. The SNP309 G allele has high affinity for the transcriptional activator SP1, which results in a higher level of MDM 2 mRNA and MDM2 protein and subsequent attenuation of the $\mathrm{p} 53$ pathway. In humans, the SNP309 G allele is associated with accelerated tumor formation in hereditary cancer associated with Li-Fraumeni syndrome and sporadic soft tissue sarcomas (14). SP1 is a well-characterized co-transcriptional activator of multiple hormone receptors, including ER. In an analysis of 3 different types of sporadic cancer (diffuse large B-cell lymphoma, soft-tissue sarcoma and invasive ductal breast carcinoma), Bond et al (15) showed that the SNP309 G allele is associated with gender-specific and hormone-dependent acceleration of tumorigenesis. Several studies, however, found no evidence of an association between SNP309 and cancer risk (16-18). The results remain controversial.

The p53 signaling pathway is activated by a wide variety of stress signals. Activation of p53 induces growth arrest, cellular senescence and apoptosis (19). Numerous polymorphisms are present in the TP53 locus. A well-known G to C SNP at TP53 codon 72 results in an arginine (Arg; CGC) or proline (Pro; CCC) polymorphism (rs1042522). This polymorphism is of particular interest owing to its functionality, although its biological function is controversial.

ESR1 is the principal ER expressed in the endometrium and is thought to be important in the development of endometrial carcinoma. The ESRI gene contains several SNPs whose functional significance remains unknown. The two most frequently studied polymorphisms located in ESRl gene intron 1 are often identified by their restriction endonucleases, $P v u I I$ T/C (rs2234693) and XbaI A/G (rs9340799).

p21, a cyclin-dependent kinase inhibitor, is the major downstream component of the TP53 tumor suppressor pathway. This protein binds to and inhibits all cyclin-dependent kinase complexes, causing cell cycle arrest in G1. The p21 codon 31 C/A (rs1801270) in exon 2 leads to a serine (Ser)/Arg amino acid substitution and is located in the DNA-binding zincfinger motif of the gene (20). This polymorphism has been implicated in cervical adenocarcinoma (21) and endometrial cancer $(22,23)$.

The MDM2 SNP309 G/G genotype increases the risk of endometrial cancer in Caucasians $(24,25)$ and in Japanese women (26). Furthermore, a combination of the homozygous Arg/Arg genotype of TP53 codon 72 and the homozygous GG genotype of MDM2 SNP309 is significantly associated with the risk of endometrial cancer in Japanese women.

We performed the present case control study to investigate the relationship between endometrial cancer risk and multiple genetic polymorphisms, including MDM2 SNP309, TP53 Arg72Pro, ESR1 PvuII and XbaI, and $p 21$ codon 31, in Japanese women.

\section{Materials and methods}

Study subjects. Subjects included 125 endometrial cancer patients who were diagnosed at the Department of Obstetrics and Gynecology of Kyushu University Hospital and Kyushu Cancer Center Hospital between 1993 and 2010. All patients provided informed consent. There was no family history of endometrial cancer in any of these cases. Control subjects were selected from 7,132 women aged 49-76 years, living in the East Ward of Fukuoka City, who had completed a baseline survey between February 2004 and August 2007 of an on-going cohort study regarding lifestyle-related diseases. Out of 2,055 women aged 49-60 years, 2,783 women aged 60-69 years, and 1,147 women aged $\geq 70$ years who had no history of cancer and who had donated a blood sample for a genetic study under signed informed consent, 106, 66 and 28 women, respectively, were randomly selected in proportion to the age distribution of the 125 cases of endometrial cancer accrued as of the end of March 2010.

Genotyping. Genomic DNA was extracted from 10-ml blood samples using the QIAamp ${ }^{\circledR}$ DNA Blood Maxi kit (Qiagen, Hilden, Germany). DNA of the controls was extracted using an automated DNA isolation system (NA-300; Kurabo, Osaka, Japan). We performed RFLP using the digested PCR products, which were electrophoresed in agarose gels and visualized using ethidium bromide. MDM2 genotyping was performed as previously described (24) using the primers 5'-CGGGAGTTCAGGGTAAAGGT-3' (sense) and 5'-AGCAAGTCGGTGCTTACCTG-3' (antisense). The PCR product of $352 \mathrm{bp}$ was digested with MspA1 (New England Biolabs, Ipswich, MA, USA). A TP53 codon 72 genotyping assay was performed as previously described (27) using primers 5'-TTGCCGTCCCAAGCAATGGATGA-3' (sense) and 5'-TCTGGGAAGGGACAGAAGATGA-3' (antisense). The restriction enzyme Bstul (New England Biolabs) was used to digest the 199-bp PCR product. The ESRl gene polymorphisms were investigated using the primers 5'-CTGCCACCCTATCTGTATCTTTTCCTATTC TCC-3' (sense) and 5'-TCTTTCTCTGCCACCCTGGCGTC GATTATCTGA-3' (antisense). The 1374-bp PCR product was digested using the restriction endonuclease $\mathrm{XbaI}$ (Takara; Shiga, Japan), or $P v u I I$ (Takara) $(28,29)$. Genotyping for the $p 21$ polymorphism was performed according to a previously published method $(30,31)$. A 245-bp fragment was amplified using the primer sets 5'-ATAGTGTCTAATCTCCGCCG-3' (sense) and 5'-AAGTCACCCTCCAGTGGTGT-3' (antisense). The 245-bp PCR product was digested using Blp 1 (New England Biolabs). To test the reliability of these assays, genotypes of the $M D M 2$, TP53, ESR1 and $p 21$ polymorphisms were validated using direct sequencing for 30 randomly selected samples of cases and controls (10 of each different genotype). The SNP309 sequencing primers used to amplify a 405-bp sequence were 5'-GATTTCGGACGGCTCTCGCGGC-3' (sense) and 5'-AGCAAGTCGGTGCTTACCTG-3' (antisense). The ESR1 $P v u I I$ and $X b a I$ sequencing primers used to amplify a 584-bp sequence were 5'-AGGTTTATGCAATGACG-3' (sense) and 5'-TCCTTGGCAGATTCCATGGC-3' (antisense). Sequencing reactions were conducted using BigDye Terminator version 3.1 (Applied Biosystems, Foster City, CA, USA). 
Table I. Characteristics of cases and controls.

\begin{tabular}{|c|c|c|c|}
\hline Characteristics & Cases, $n=125$ & Controls, $n=200$ & P-value \\
\hline Age (years, median) & $27-88(56)$ & $49-75(59)$ & $<0.0001$ \\
\hline \multicolumn{4}{|l|}{ Menopausal status (\%) } \\
\hline Premenopausal & $47(37.6)$ & $17(8.5)$ & $<0.05$ \\
\hline Postmenopausal & $78(62.4)$ & $183(91.5)$ & $<0.05$ \\
\hline \multicolumn{4}{|l|}{ Parity (\%) } \\
\hline Never & $37(29.6)$ & $20(10.0)$ & $<0.05$ \\
\hline Ever & $88(70.4)$ & $180(90.0)$ & $<0.05$ \\
\hline BMI $\left(\mathrm{kg} / \mathrm{m}^{2}\right)$ mean $(\mathrm{SD})$ & $24.2(5.0)$ & $22.9(3.0)$ & $<0.0001$ \\
\hline$<25(\%)$ & $76(60.8)$ & $162(81.0)$ & \\
\hline$\geq 25(\%)$ & 49 (39.2) & $38(19.0)$ & \\
\hline \multicolumn{4}{|l|}{ FIGO stage $(\%)$} \\
\hline I & $95(76.0)$ & & \\
\hline II & $7(5.6)$ & & \\
\hline III & $19(15.2)$ & & \\
\hline IV & $3(2.4)$ & & \\
\hline Unknown $^{\mathrm{a}}$ & $1(0.8)$ & & \\
\hline \multicolumn{4}{|l|}{ Histology } \\
\hline Endometrioid adenocarcinoma (\%) & $112(89.6)$ & & \\
\hline Grade 1 & 74 & & \\
\hline Grade 2 & 28 & & \\
\hline Grade 3 & 10 & & \\
\hline Non-endometrioid adenocarcinoma (\%) & $13(10.4)$ & & \\
\hline Serous papillary adenocarcinoma & 4 & & \\
\hline Clear cell adenocarcinoma & 3 & & \\
\hline Mixed $^{\mathrm{b}}$ & 3 & & \\
\hline Undifferentiated & 1 & & \\
\hline Neuroendocrine carcinoma & 1 & & \\
\hline Squamous cell carcinoma & 1 & & \\
\hline
\end{tabular}

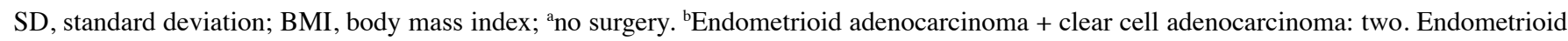
adenocarcinoma + serous papillary adenocarcinoma: one.

Cell culture. Endometrial cancer cell lines were maintained in DMEM supplemented with 10\% FBS for HHUA and 15\% FBS for Hec6 and Sawano cells.

Cell growth assay. Cells were plated in a $6-\mathrm{cm}$ dish at $1 \times 10^{5}$ cells/dish and incubated with a medium supplemented for $24 \mathrm{~h}$. Subsequently, to reactivate p53 and induce tumor cell apoptosis, the compound RITA (Tocris, Ellisville, MO, USA), was added, and the cells were further incubated for 48 and 96 h. Following incubation, floating cells were washed away and adherent cells were detached from the dishes using $0.25 \%$ trypsin. Detached cells were then counted using a hemocytometer.

Statistical analysis. Comparisons of means and proportions between cases and controls were performed using the t-test and Chi-square test, respectively. Deviation from the HardyWeinberg equilibrium was evaluated using the Chi-square test with 1 degree of freedom. The association of each genetic polymorphism with endometrial cancer was examined by the odds ratio (OR) and the $95 \%$ confidence interval $(95 \% \mathrm{CI})$, which were obtained using logistic regression analysis. The 95\% CI was derived from the standard error of the logistic regression coefficient. Statistical adjustment was made for age and body mass index (BMI) with continuous variables for each included as covariates. Trends in ORs according to the number of minor alleles were evaluated using the Wald test. For analyzing the interaction between two polymorphisms, heterozygous and homozygous genotypes of the minor alleles were combined and statistical evaluation was conducted using the Wald test for the product term of the two variables representing the genotypes containing the minor allele. Statistical significance was declared if a two-sided P-value $<0.05$ or if the $95 \%$ CI did not include unity. Statistical analyses were carried out using SAS version 8.2 (SAS Institute Inc., Cary, NC, USA). 
Table II. MDM2, TP53, ESR 1 and $p 21$ genotypes and endometrial cancer risk.

\begin{tabular}{|c|c|c|c|c|}
\hline Genotype & $\begin{array}{c}\text { Cases, } n=125 \\
(\%)\end{array}$ & $\begin{array}{c}\text { Controls, } \mathrm{n}=200 \\
(\%)\end{array}$ & $\begin{array}{l}\text { Crude OR } \\
(95 \% \mathrm{CI})\end{array}$ & $\begin{array}{l}\text { Adjusted }^{\mathrm{a}} \text { OR } \\
(95 \% \mathrm{CI})\end{array}$ \\
\hline \multicolumn{5}{|l|}{ MDM2 SNP309 } \\
\hline $\mathrm{TT}$ & $30(24.0)$ & $62(31.0)$ & 1.00 (reference) & 1.00 (reference) \\
\hline $\mathrm{TG}$ & $61(48.8)$ & $98(49.0)$ & $1.29(0.75-2.21)$ & $1.09(0.60-1.99)$ \\
\hline GG & $34(27.2)$ & $40(20.0)$ & $\begin{array}{c}1.76(0.93-3.30) \\
\text { P-trend }=0.08\end{array}$ & $\begin{array}{c}1.64(0.81-3.28) \\
\text { P-trend }=0.45\end{array}$ \\
\hline $\mathrm{TG}+\mathrm{GG}$ & $95(76.0)$ & $138(69.0)$ & $1.42(0.86-2.37)$ & $1.24(0.70-2.18)$ \\
\hline \multicolumn{5}{|l|}{ TP53 codon 72} \\
\hline Arg/Arg & $52(41.6)$ & 75 (37.5) & 1.00 (reference) & 1.00 (reference) \\
\hline Arg/Pro & $55(44.0)$ & $102(51.0)$ & $0.78(0.48-1.26)$ & $0.66(0.38-1.15)$ \\
\hline Pro/Pro & $18(14.4)$ & $23(11.5)$ & $\begin{array}{c}1.13(0.55-2.30) \\
\text { P-trend }=0.08\end{array}$ & $\begin{array}{c}1.17(0.54-2.55) \\
\text { P-trend }=0.79\end{array}$ \\
\hline Arg/Pro + Pro/Pro & $73(58.4)$ & $125(62.5)$ & $0.84(0.53-1.33)$ & $0.76(0.46-1.27)$ \\
\hline \multicolumn{5}{|l|}{ ESRI PvuII } \\
\hline $\mathrm{TT}$ & $38(30.4)$ & $60(30.0)$ & 1.00 (reference) & 1.00 (reference) \\
\hline $\mathrm{TC}$ & $60(48.0)$ & $102(51.0)$ & $0.93(0.55-1.56)$ & $0.94(0.55-1.56)$ \\
\hline $\mathrm{CC}$ & $27(21.5)$ & $38(19.0)$ & $\begin{array}{c}1.12(0.59-2.13) \\
\text { P-trend }=0.78\end{array}$ & $\begin{array}{c}0.89(0.43-1.86) \\
\text { P-trend }=0.76\end{array}$ \\
\hline $\mathrm{TC}+\mathrm{CC}$ & 87 (69.6) & $140(70.0)$ & $0.98(0.60-1.60)$ & $0.93(0.53-1.60)$ \\
\hline \multicolumn{5}{|l|}{ ESR1 XbaI } \\
\hline $\mathrm{AA}$ & 77 (61.6) & $127(63.5)$ & 1.00 (reference) & 1.00 (reference) \\
\hline $\mathrm{AG}$ & $42(33.6)$ & $64(32.0)$ & $1.08(0.67-1.75)$ & $0.88(0.51-1.53)$ \\
\hline GG & $6(4.8)$ & $9(4.5)$ & $\begin{array}{c}1.10(0.38-3.21) \\
\text { P-trend }=0.74\end{array}$ & $\begin{array}{c}0.60(0.16-2.24) \\
P \text {-trend }=0.43\end{array}$ \\
\hline $\mathrm{AG}+\mathrm{GG}$ & $48(38.4)$ & $73(36.5)$ & $1.09(0.68-1.72)$ & $0.84(0.50-1.43)$ \\
\hline \multicolumn{5}{|l|}{ p21 codon 31} \\
\hline Ser/Ser & $21(16.8)$ & $38(19.0)$ & 1.00 (reference) & 1.00 (reference) \\
\hline Ser/Arg & $73(58.4)$ & $109(54.5)$ & $1.21(0.66-2.23)$ & $1.13(0.57-2.22)$ \\
\hline Arg/Arg & $31(24.8)$ & $53(26.5)$ & $\begin{array}{c}1.06(0.53-2.12) \\
\text { P-trend }=0.95\end{array}$ & $\begin{array}{c}1.01(0.47-2.19) \\
\text { P-trend }=0.98\end{array}$ \\
\hline Ser/Arg + Arg/Arg & 104 (83.2) & $162(81.0)$ & $1.16(0.65-2.09)$ & $1.09(0.57-2.09)$ \\
\hline
\end{tabular}

OR, odds ratio; adjusted for age and BMI.

\section{Results}

Characteristics of endometrial cancer cases and controls. Selected characteristics of endometrial cancer cases and controls are shown in Table I. The mean age in the cases group was lower than that of the control group as the latter were selected from women aged 49-76 years, while the former were recruited regardless of age. BMI was significantly greater in cases than in controls. A total of $49(39.2 \%)$ overweight women $\left(\mathrm{BMI} \geq 25 \mathrm{~kg} / \mathrm{m}^{2}\right)$ were included in the cases and $38(19.0 \%)$ in the controls $(\mathrm{P}<0.001)$. Most tumors $(112,89.6 \%)$ were of endometrioid histology. Most cases were of The International Federation of Gynecology and Obstetrics (FIGO) stage I (95, $76.0 \%)$.

Frequencies of variant alleles between cases and controls respectively were as follows: SNP309 G allele (0.516 and 0.445), TP53 codon 72 Pro allele (0.364 and 0.370), ESR 1 PvuII
C allele (0.456, 0.445), ESRI XbaI G allele (0.216, 0.205), and p21 codon 31 Ser allele (0.460 and 0.463). Genotype distributions of the SNP309, TP53 Arg72Pro, ESR1 PvuII and XbaI, and $p 21$ codon 31 polymorphisms in the controls did not deviate from Hardy-Weinberg equilibrium.

The MDM2 SNP309, TP53, ESR1 and 21 polymorphisms do not individually increase the risk of endometrial cancer development. Table II shows the association between endometrial cancer risk and SNP309, TP53, ESR1 and p21 polymorphisms. The OR for the SNP309 GG genotype when compared with the SNP309 TT genotype non-significantly increased risk. The crude OR was 1.76 (95\% CI, 0.93-3.30), and the age- and BMI-adjusted OR was 1.64 (95\% CI, 0.81-3.28). There was also no measurable association between endometrial cancer and the TP53 Arg72Pro, ESRl PvuII and XbaI, or the $p 21$ codon 31 polymorphisms. Adjustment for age and BMI did 
Table III. MDM2 and TP53 genotypes and endometrial cancer risk.

\begin{tabular}{|c|c|c|c|c|}
\hline Genotype & $\begin{array}{l}\text { No. of cases } \\
(\%)\end{array}$ & $\begin{array}{l}\text { No. of controls } \\
(\%)\end{array}$ & $\begin{array}{l}\text { Crude OR } \\
(95 \% \mathrm{CI})\end{array}$ & $\begin{array}{l}\text { Adjusted }^{\mathrm{a}} \text { OR } \\
\quad(95 \% \mathrm{CI})\end{array}$ \\
\hline $\begin{array}{l}\text { Postmenopause } \\
\text { MDM2 SNP309 }\end{array}$ & \multicolumn{4}{|c|}{ MDM2 SNP309 } \\
\hline $\mathrm{TT}$ & $22(28.2)$ & $57(31.1)$ & 1.00 (reference) & 1.00 (reference) \\
\hline $\mathrm{TG}$ & $36(46.2)$ & $90(49.2)$ & $1.04(0.55-1.94)$ & $1.12(0.59-2.15)$ \\
\hline GG & $20(25.6)$ & $36(19.7)$ & $\begin{array}{c}1.44(0.69-3.00) \\
\text { P-trend }=0.36\end{array}$ & $\begin{array}{c}1.60(0.75-3.43) \\
\text { P-trend }=0.24\end{array}$ \\
\hline $\mathrm{TG}+\mathrm{GG}$ & $56(71.8)$ & $126(68.9)$ & $1.15(0.64-2.07)$ & $1.26(0.69-2.31)$ \\
\hline \multicolumn{5}{|l|}{ TP53 codon 72} \\
\hline Arg/Arg & $33(42.3)$ & $69(37.7)$ & 1.00 (reference) & 1.00 (reference) \\
\hline Arg/Pro & $32(41.0)$ & $93(50.8)$ & $0.72(0.40-1.28)$ & $0.79(0.43-1.43)$ \\
\hline Pro/Pro & $13(16.7)$ & $21(11.5)$ & $\begin{array}{c}1.29(0.58-2.90) \\
\text { P-trend }=0.95\end{array}$ & $\begin{array}{c}1.44(0.63-3.31) \\
\text { P-trend }=0.70\end{array}$ \\
\hline Arg/Pro + Pro/Pro & $45(57.7)$ & $114(62.3)$ & $0.83(0.48-1.42)$ & $0.91(0.52-1.58)$ \\
\hline \multicolumn{5}{|l|}{ Type $1^{b}$} \\
\hline MDM2 SNP309 & $\mathrm{n}=102$ & $\mathrm{n}=200$ & & \\
\hline $\mathrm{TT}$ & $26(25.5)$ & $62(31.0)$ & 1.00 (reference) & 1.00 (reference) \\
\hline $\mathrm{TG}$ & $47(46.1)$ & $98(49.0)$ & $1.14(0.64-2.03)$ & $0.88(0.46-1.72)$ \\
\hline GG & $29(28.4)$ & $40(20.0)$ & $\begin{array}{c}1.73(0.89-3.35) \\
\text { P-trend }=0.11\end{array}$ & $\begin{array}{c}1.56(0.73-3.33) \\
\text { P-trend }=0.30\end{array}$ \\
\hline $\mathrm{TG}+\mathrm{GG}$ & $76(74.5)$ & $138(69.0)$ & $1.31(0.76-2.25)$ & 1.07 (0.58-1.97) \\
\hline \multicolumn{5}{|l|}{ TP53 codon 72} \\
\hline Arg/Arg & $45(44.1)$ & $75(37.5)$ & 1.00 (reference) & 1.00 (reference) \\
\hline Arg/Pro & $44(43.1)$ & $102(51.0)$ & $0.79(0.43-1.20)$ & $0.55(0.30-1.02)$ \\
\hline Pro/Pro & $13(12.8)$ & $23(11.5)$ & $\begin{array}{c}0.94(0.43-2.04) \\
\text { P-trend }=0.51\end{array}$ & $\begin{array}{c}1.00(0.42-2.38) \\
\text { P-trend }=0.43\end{array}$ \\
\hline Arg/Pro + Pro/Pro & $57(55.9)$ & $125(62.5)$ & $0.76(0.47-1.23)$ & $0.64(0.36-1.12)$ \\
\hline $\begin{array}{l}\text { Postmenopause }+ \text { type } 1 \\
\text { MDM2 SNP309 }\end{array}$ & \multicolumn{3}{|c|}{ MDM2 SNP309 } & \\
\hline TT & $19(32.2)$ & $57(31.1)$ & 1.00 (reference) & 1.00 (reference) \\
\hline TG & $25(42.4)$ & $90(49.2)$ & $0.83(0.42-1.65)$ & $0.94(0.46-1.93)$ \\
\hline GG & $15(25.4)$ & $36(19.7)$ & $\begin{array}{c}1.25(0.56-2.77) \\
\text { P-trend }=0.66\end{array}$ & $\begin{array}{c}1.50(0.64-3.47) \\
\text { P-trend }=0.40\end{array}$ \\
\hline $\mathrm{TG}+\mathrm{GG}$ & $40(67.8)$ & $126(69.9)$ & $0.95(0.51-1.79)$ & $1.09(0.56-2.13)$ \\
\hline \multicolumn{5}{|l|}{ TP53 codon 72} \\
\hline Arg Arg & $28(47.5)$ & $69(37.7)$ & 1.00 (reference) & 1.00 (reference) \\
\hline Arg/Pro & $22(37.3)$ & $93(50.8)$ & $0.58(0.31-1.11)$ & $0.66(0.34-1.30)$ \\
\hline Pro/Pro & $9(15.2)$ & $21(11.5)$ & $\begin{array}{c}1.06(0.43-2.59) \\
\text { P-trend }=0.55\end{array}$ & $\begin{array}{c}1.24(0.49-3.16) \\
\text { P-trend }=0.89\end{array}$ \\
\hline Arg/Pro + Pro/Pro & $31(52.5)$ & $114(62.3)$ & $0.67(0.37-1.21)$ & $0.77(0.41-1.43)$ \\
\hline
\end{tabular}

OR, odds ratio; adjusted for age and BMI. ${ }^{\mathrm{b}}$ Type 1; endometrioid adenocarcinoma G1 and G2.

not significantly alter the results. The analysis was repeated with stratification by menopausal status, histological status (Table III) and overweight status. There were 261 postmenopausal women (78 cases and 183 controls) and 102 women with type I endometrial cancer. For SNP309, the OR associated with the $G$ allele, a slight increase was seen with postmenopausal status and type I status in cases that were not statistically significant. When the analysis was confined to overweight women (49 cases and 38 controls), the adjusted SNP309 OR for GG vs. TT was 2.39 (95\% CI, 0.59-9.66).

Combination of the MDM2 SNP309 $G$ allele and the Arg/ Arg genotype of TP53 codon 72 interacts significantly to affect the risk of endometrial cancer. In the analysis of 
Table IV. Endometrial cancer risk for combined effect of MDM2 and TP53 genotypes.

\begin{tabular}{|c|c|c|c|c|c|}
\hline Genotype & & $\begin{array}{l}\text { No. of cases } \\
(\%)\end{array}$ & $\begin{array}{c}\text { No. of controls } \\
(\%)\end{array}$ & $\begin{array}{l}\text { Crude OR } \\
(95 \% \mathrm{CI})\end{array}$ & $\begin{array}{l}\text { Adjusted }^{\mathrm{a}} \text { OR } \\
\quad(95 \% \mathrm{CI})\end{array}$ \\
\hline All & & $\mathrm{n}=125$ & $\mathrm{n}=200$ & & \\
\hline MDM2 SNP309 & TP53 codon 72 & & & & \\
\hline $\mathrm{TT}$ & Arg/Arg & $10(8.0)$ & $28(14.0)$ & 1.00 (reference) & 1.00 (reference) \\
\hline TT & Arg/Pro + Pro Pro & $20(16.0)$ & $34(17.0)$ & $1.65(0.66-4.09)$ & $1.79(0.68-4.73)$ \\
\hline $\mathrm{TG}+\mathrm{GG}$ & Arg/Arg & $42(33.6)$ & $47(23.5)$ & $2.50(1.09-5.75)$ & $2.53(1.03-6.21)$ \\
\hline $\mathrm{TG}+\mathrm{GG}$ & Arg/Pro + Pro/Pro & $53(42.4)$ & $91(45.5)$ & $\begin{array}{c}1.63(0.73-3.62) \\
\text { P-interaction }=0.09\end{array}$ & $\begin{array}{c}1.35(0.56-3.24) \\
\text { P-interaction }=0.04\end{array}$ \\
\hline Postmenopause & & $\mathrm{n}=78$ & $\mathrm{n}=183$ & & \\
\hline MDM2 SNP309 & TP53 codon 72 & & & & \\
\hline $\mathrm{TT}$ & Arg/Arg & $6(7.7)$ & $25(13.7)$ & 1.00 (reference) & 1.00 (reference) \\
\hline $\mathrm{TT}$ & Arg/Pro + Pro/Pro & $16(20.5)$ & $32(17.5)$ & $2.08(0.71-6.10)$ & $2.46(0.81-7.44)$ \\
\hline $\mathrm{TG}+\mathrm{GG}$ & Arg/Arg & $27(34.6)$ & $44(24.0)$ & $2.56(0.93-7.03)$ & $2.96(1.04-8.44)$ \\
\hline $\mathrm{TG}+\mathrm{GG}$ & Arg/Pro + Pro/Pro & $29(37.2)$ & $82(44.8)$ & $\begin{array}{c}1.47(0.55-3.95) \\
\text { P-interaction }=0.04\end{array}$ & $\begin{array}{c}1.84(0.66-5.16) \\
\text { P-interaction }=0.03\end{array}$ \\
\hline Type $1^{\mathrm{b}}$ & & $\mathrm{n}=102$ & $n=200$ & & \\
\hline MDM2 SNP309 & TP53 codon 72 & & & & \\
\hline $\mathrm{TT}$ & Arg/Arg & $9(8.8)$ & $28(14.0)$ & 1.00 (reference) & 1.00 (reference) \\
\hline $\mathrm{TT}$ & Arg/Pro + Pro/Pro & $17(16.7)$ & $34(17.0)$ & $1.55(0.60-4.02)$ & $1.82(0.65-5.11)$ \\
\hline $\mathrm{TG}+\mathrm{GG}$ & Arg/Arg & $36(35.3)$ & $47(23.5)$ & $2.38(1.00-5.67)$ & $2.51(0.97-6.53)$ \\
\hline $\mathrm{TG}+\mathrm{GG}$ & Arg/Pro + Pro/Pro & $40(39.2)$ & $91(45.5)$ & $\begin{array}{c}1.37(0.59-3.16) \\
\text { P-interaction }=0.07\end{array}$ & $\begin{array}{c}0.98(0.37-2.58) \\
\text { P interaction }=0.01\end{array}$ \\
\hline Postmenopause + Type 1 & & $\mathrm{n}=59$ & $\mathrm{n}=183$ & & \\
\hline MDM2 SNP309 & TP53 codon 72 & & & & \\
\hline $\mathrm{TT}$ & Arg/Arg & $5(8.5)$ & $25(13.7)$ & 1.00 (reference) & 1.00 (reference) \\
\hline $\mathrm{TT}$ & Arg/Pro + Pro/Pro & $14(23.7)$ & $32(17.5)$ & $2.19(0.70-6.89)$ & $2.76(0.83-9.19)$ \\
\hline $\mathrm{TG}+\mathrm{GG}$ & Arg/Arg & $23(39.0)$ & $44(24.0)$ & $2.61(0.88-7.73)$ & $3.24(1.03-10.16)$ \\
\hline $\mathrm{TG}+\mathrm{GG}$ & Arg/Pro + Pro/Pro & $17(28.8)$ & $82(44.8)$ & $\begin{array}{c}1.04(0.35-3.09) \\
\text { P-interaction=0 } 01\end{array}$ & $\begin{array}{c}1.43(0.45-4.57) \\
\text { P interaction }=0.009\end{array}$ \\
\hline
\end{tabular}

OR; odds ratio; CI; confidence interval. a Adjusted for age and BMI. ' $T y p e$ 1, endometrioid adenocarcinoma G1 and G2.

the combination of the two polymorphisms (Table IV), the SNP309 TG and GG genotypes as well as the TP53 Arg/Pro and TP53 Pro/Pro genotypes were combined. A significant increase in the adjusted OR associated with the SNP309 $\mathrm{G}$ allele was limited to those homozygous for the TP53 Arg allele (OR, 2.53; 95\% CI, 1.03-6.21). A statistically significant interaction was observed between the 2 polymorphisms on the risk of endometrial cancer ( $\mathrm{P}$ for the interaction=0.04). We repeated the analysis to include postmenopausal status and type I endometrial cancer status. Adjusted ORs for postmenopausal women and type I women possessing both polymorphisms when compared with being homozygous for both wild-type alleles were 2.96 (95\% CI, 1.04-8.44) and 2.51 (95\% CI, 0.97-6.53), respectively. There was a statistically significant interaction between the two polymorphisms regarding the risk of endometrial cancer $(\mathrm{P}$ for the interaction $=0.03$ and 0.01 , respectively). Moreover, the corresponding value for type I among postmenopausal women (59 cases) was 3.24 (95\% CI, 1.03-10.16), which reflected a statistically significant interaction between the SNP309 and TP53 Arg72Pro polymorphisms (P for the interaction $=0.009$ ).

Combination of the TP53 72Pro allele and homozygosity for the p21 codon 31 Ser allele is associated with a decreased risk of endometrial cancer. We further examined the effect of SNP309 combined with ESR1 or p21 and SNP309 with both TP53 and $p 21$ polymorphisms on the risk of endometrial cancer (Table V). No significant differences were observed between the combination of the SNP309 and the PvuII or $X b a \mathrm{I}$ or $p 21$ polymorphism. The combination of having the TP53 72Pro allele and homozygosity for the $p 21$ codon 31 Ser allele, however, was associated with a decreased risk of endometrial cancer (crude OR, 0.28; 95\% CI, 0.09-0.92). A statistically significant interaction was observed between the 2 polymorphisms for a decreased risk of endometrial cancer ( $\mathrm{P}$ for the interaction=0.04), although there was no significant difference once adjustment was made for age and BMI. 
Table V. Endometrial cancer risk for combined effect of MDM2, TP53, ESR 1 and $p 21$ genotypes.

\begin{tabular}{|c|c|c|c|c|c|}
\hline Genotype & & $\begin{array}{c}\text { Cases, } \mathrm{n}=125 \\
(\%)\end{array}$ & $\begin{array}{c}\text { Controls, } \mathrm{n}=200 \\
(\%)\end{array}$ & $\begin{array}{l}\text { Crude OR } \\
(95 \% \mathrm{CI})\end{array}$ & $\begin{array}{l}\text { Adjusted }^{\mathrm{a}} \text { OR } \\
\quad(95 \% \mathrm{CI})\end{array}$ \\
\hline MDM2 SNP309 & ESR1 PvuII & & & & \\
\hline $\mathrm{TT}$ & $\mathrm{TT}$ & $8(6.4)$ & $20(10.0)$ & 1.00 (reference) & 1.00 (reference) \\
\hline $\mathrm{TT}$ & $\mathrm{TC}+\mathrm{CC}$ & $22(17.6)$ & $42(21.0)$ & $1.31(0.50-3.45)$ & $0.96(0.34-2.69)$ \\
\hline $\mathrm{TG}+\mathrm{GG}$ & TT & $30(24.0)$ & $40(20.0)$ & $1.86(0.73-4.83)$ & $1.29(0.47-3.57)$ \\
\hline $\mathrm{TG}+\mathrm{GG}$ & $\mathrm{TC}+\mathrm{CC}$ & $65(52.0)$ & $98(49.0)$ & $\begin{array}{c}1.66(0.69-3.99) \\
\text { P-interaction }=0.49\end{array}$ & $\begin{array}{c}1.18(0.46-2.99) \\
\text { P-interaction }=0.93\end{array}$ \\
\hline MDM2 SNP309 & ESRl XbaI & & & & \\
\hline $\mathrm{TT}$ & AA & $20(16.0)$ & $42(21.0)$ & 1.00 (reference) & 1.00 (reference) \\
\hline $\mathrm{TT}$ & $\mathrm{AG}+\mathrm{GG}$ & $10(8.0)$ & $20(10.0)$ & $1.05(0.42-2.65)$ & $0.83(0.30-2.23)$ \\
\hline $\mathrm{TG}+\mathrm{GG}$ & AA & $57(45.6)$ & $85(42.5)$ & $1.41(0.75-2.64)$ & $1.25(0.63-2.47)$ \\
\hline $\mathrm{TG}+\mathrm{GG}$ & $\mathrm{AG}+\mathrm{GG}$ & $38(30.4)$ & $53(26.5)$ & $\begin{array}{c}1.51(0.77-2.96) \\
\text { P interaction }=0.97\end{array}$ & $\begin{array}{c}1.05(0.49-2.23) \\
\text { P-interaction }=0.96\end{array}$ \\
\hline MDM2 SNP309 & p21 codon 31 & & & & \\
\hline $\mathrm{TT}$ & Ser/Ser & $8(6.4)$ & $11(5.5)$ & 1.00 (reference) & 1.00 (reference) \\
\hline $\mathrm{TT}$ & Ser/Arg + Arg/Arg & $22(17.6)$ & $51(25.5)$ & $0.59(0.21-1.68)$ & $0.58(0.19-1.75)$ \\
\hline $\mathrm{TG}+\mathrm{GG}$ & Ser/Ser & $13(10.4)$ & $27(13.5)$ & $0.66(0.22-2.04)$ & $0.58(0.17-2.00)$ \\
\hline $\mathrm{TG}+\mathrm{GG}$ & Ser/Arg + Arg/Arg & $82(65.6)$ & $111(55.5)$ & $\begin{array}{c}1.02(0.39-2.64) \\
\text { P-interaction }=0.14\end{array}$ & $\begin{array}{c}0.87(0.31-2.41) \\
\text { P-interaction }=0.18\end{array}$ \\
\hline TP53 codon 72 & p21 codon 31 & & & & \\
\hline Arg/Arg & Ser/Ser & $16(12.8)$ & $18(9.0)$ & 1.00 (reference) & 1.00 (reference) \\
\hline Arg/Arg & Ser/Arg + Arg/Arg & $36(28.8)$ & $57(28.5)$ & $0.71(0.32-1.57)$ & $0.85(0.35-2.02)$ \\
\hline Arg/Pro + Pro/Pro & Ser/Ser & $5(4.0)$ & $20(10.0)$ & $0.28(0.09-0.92)$ & $0.39(0.11-1.43)$ \\
\hline Arg/Pro + Pro/Pro & Ser/Arg + Arg/Arg & $68(54.4)$ & $105(52.5)$ & $\begin{array}{c}0.73(0.35-1.53) \\
\text { P-interaction }=0.04\end{array}$ & $\begin{array}{c}0.72(0.32-1.64) \\
\text { P-interaction }=0.27\end{array}$ \\
\hline
\end{tabular}

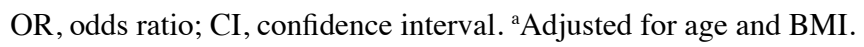

The SNP309 GG genotype abrogates the cytostatic effect of RITA on tumor cells. MDM2 overexpression is observed in multiple malignancies. Due to the importance of the p53-MDM2 interaction, restoration of p53 activity by inhibiting MDM2 binding represents a novel antineoplastic strategy. RITA is a low-molecular-weight compound previously identified in a cell-based screen for wild-type p53-reactivating compounds. RITA binds to the amino terminus of p53, inhibiting p53 binding to MDM2 in cultured cells and in human tumor xenografts in vivo. This results in derepression of $\mathrm{p} 53$ and highly efficient induction of apoptosis (32).

We demonstrated that a combination of the SNP309 $\mathrm{G}$ allele and the homozygous Arg/Arg genotype of TP53 codon 72 was associated with an increased risk of endometrial cancer (Table IV). These results suggest that polymorphisms of MDM2 and TP53 may influence the effect of RITA. We therefore, assessed the growth-suppressive effect of RITA on three endometrial cancer cell lines, Hec6, HHUA and Sawano, in vitro. All three lines express wild-type p53. SNP309 and TP53 Arg72Pro polymorphisms were analyzed in these lines with PCR-RFLP and direct sequencing. Hec6 cells were SNP309 TT homozygous and TP53 Arg72 homozygous, HHUA cells were SNP309 TG heterozygous and TP53 Arg72
Table VI. Genotype of endometrial cancer cell lines.

\begin{tabular}{lccc}
\hline Cell line & MDM2 SNP309 & TP53 codon 72 & TP53 status \\
\hline Hec6 & TT & Arg/Arg & Wild-type \\
HHUA & TG & Arg/Arg & Wild-type \\
Sawano & GG & Arg/Pro & Wild-type \\
\hline
\end{tabular}

homozygous, and Sawano cells were SNP309 GG homozygous and TP53 Arg72Pro heterozygous (Table VI). Treatment with RITA $(0.5$ and $1.0 \mu \mathrm{M})$ suppressed cell growth in all cell lines in a dose-dependent manner (Fig. 1A). Following treatment with $0.5 \mu \mathrm{M}$ RITA for four days, the rates of inhibition

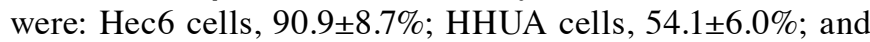
Sawano cells, $49.0 \pm 15.8 \%$. Following treatment with $1.0 \mu \mathrm{M}$ RITA, these rates were $94.3 \pm 1.2 \%, 79.0 \pm 4.6 \%$ and $61.0 \pm 6.7 \%$, respectively. The inhibitory effect was significantly less pronounced in HHUA and Sawano cells with the SNP309 G allele compared to that in Hec 6 cells carrying the SNP309 TT genotype $(\mathrm{P}<0.05)$ (Fig. 1B). 
A
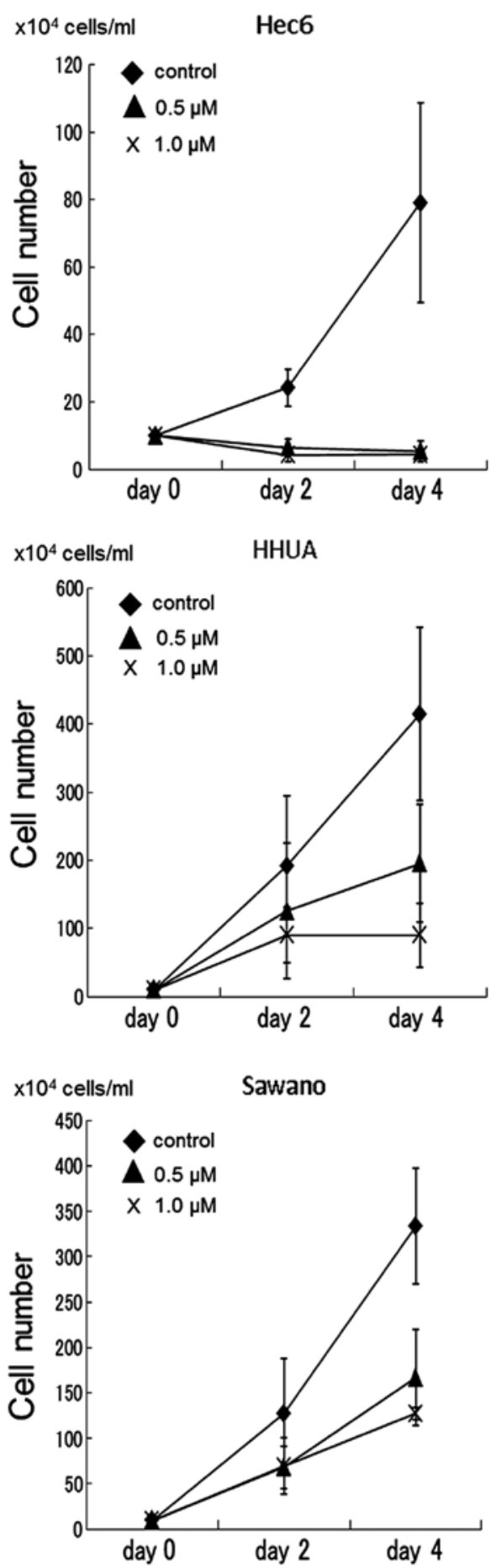

\section{Discussion}

The present study investigated the associations of endometrial cancer risk with the MDM2 SNP309, TP53 Arg72Pro, ESR1

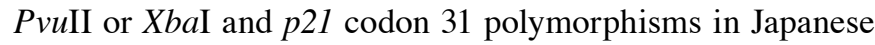
women. Although each polymorphism individually was unrelated to endometrial cancer risk, the SNP309 G allele was associated with an increased risk in women homozygous for the TP53 codon 72 Arg allele. Furthermore, the relationship remained significant in a subgroup analysis (postmenopausal, type I endometrial cancer and overweight status. These were related to unopposed estrogen).
B

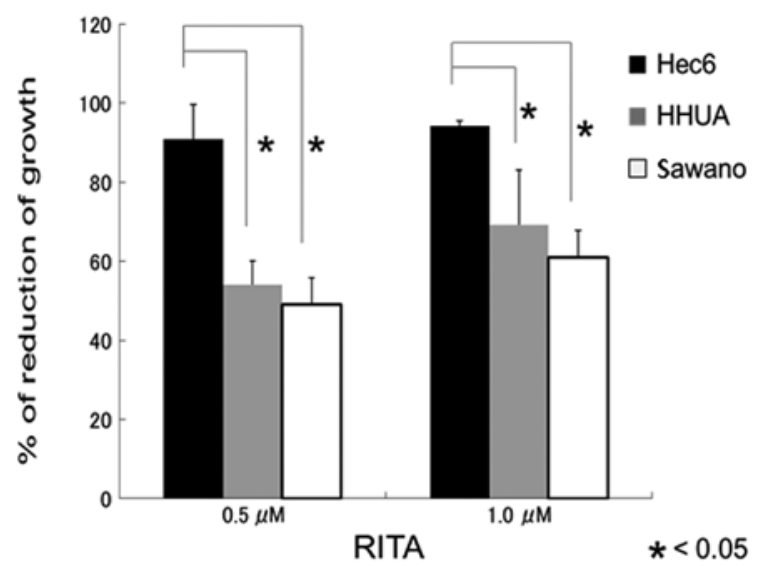

Figure 1. Growth inhibitory effects of RITA on endometrial cancer cell lines (A) Treatment with RITA inhibited cell growth in endometrial cancer cell lines. Following treatment with DMSO (control) or 0.1 or $0.5 \mu \mathrm{M}$ RITA for two or four days for three endometrial cancer cell lines (Hec6, HHUA and Sawano), viable cells were counted. Experiments were performed in triplicate. Vertical bars indicate SDs. (B) The SNP309 G allele inhibited the cytostatic property of RITA in tumor cells. Following treatment with DMSO and RITA for four days, viable cells were counted and the reduction in the rate of growth was calculated. Vertical bars indicate SDs. ${ }^{*} \mathrm{P}<0.05$.

Few studies have addressed the association of SNP309 with the risk of endometrial cancer. Walsh et al (24) reported an OR of 2.76 for the GG vs. the TT genotype $(95 \% \mathrm{CI}$, 1.06-7.20) in a United States case-control study. In a nested case-control study of Caucasian women, an OR of 1.87 (95\% CI, 1.29-2.73) was reported for the GG genotype compared with the TT genotype (Nurses' Health Study, 454 cases and 1,132 controls; Women's Health Study, 137 cases and 411 controls) (25). Ashton et al (33), however, failed to document a similar association in an Australian study.

The association between the TP53 Arg72Pro polymorphism and endometrial cancer risk has been investigated in several studies in Caucasians with inconsistent findings. The following findings have been reported for women of Asian descent: Ueda et al (27) reported an increased risk of endometrial cancer in Japanese patients harboring the Arg/Arg genotype compared to those with Arg/Pro and Pro/Pro genotypes combined. Niwa et al (34), however, found no such association. By contrast, having the Pro allele conferred an increased risk in Korean women (22).

Two studies have reported a potential interaction between the SNP309 G allele and the TP53 Arg72Pro polymorphisms for endometrial cancer. Nunobiki et al (35) showed that the risk with the SNP309 GG vs. TT or TG was greater in women with $\mathrm{Arg} / \mathrm{Arg}$ (OR, 3.28; 95\% CI, 1.13-9.53) than in women with Arg/Pro or Pro/Pro of the TP53 Arg72Pro (OR, 1.48; 95\% CI, 0.62-3.52), but the interaction between the two SNPs was not evaluated.

Ashton et al (33) showed noeffect of the TP53 polymorphism and MDM2 SNP309 alone or in combination on endometrial cancer risk. They did, however, show that the combination of SNP309 and TP53 was associated with high-grade endometrial cancer $(\mathrm{G} 2+\mathrm{G} 3)$. These observations are incompatible with the findings of the present study showing that the combination of SNP309 and TP53 was associated with type I endometrial 
cancer $(\mathrm{G} 1+\mathrm{G} 2)$. This discrepancy may have arisen due to the fact that G2 and G3 are classified as high-grade tumors. G3 tumors are a distinct entity. For example, in Japanese women, p53 mutations are significantly more common in G3 (43\%) than in $\mathrm{G1}(11 \%)$ tumors (36). p53 mutations are also detected more frequently in type II endometrial cancer. Tumors harboring p53 mutations are often more chemoresistant and have lower apoptotic rates. The status of the TP53 gene (wild-type or mutant type) is critical when determining the relationship between grade and a TP53 polymorphism. In the present study, an analysis of 102 cases that were not type II demonstrated a significant interaction between the MDM2 SNP309 and TP53 Arg72Pro polymorphism with endometrial cancer risk. We did not, however, ascertain whether the combination of MDM2 and TP53 Arg72Pro was associated with high-grade or nonendometrioid tumors as the overall number of these cases (G3, 10 cases; non-endometrioid, 13 cases) was small.

A major limitation of the present study was its small size. As most of the women with endometrial cancer are early stage and have positive outcomes, it was difficult to analyze the association between studied polymorphisms and disease outcome in the present study.

Five meta-analyses have been published addressing the MDM2 SNP309 polymorphism and the risk of various types of tumor. Wilkening et al (37) combined the available genotype data for breast, colorectal and lung cancer. These results suggest that the SNP309 variant does not have an impact on the risk of breast or colorectal cancer. The OR for lung cancer, however, revealed an increased risk for GG vs. TT (OR, 1.27; 95\% CI, 1.12-1.44). Hu et al (38) conducted a meta-analysis with different tumor types, including endometrial cancer. The OR revealed an increased risk for GG vs. TT (OR, 1.17; 95\% CI, 1.04-1.33), and (OR, 1.37; 95\% CI, 1.23-1.53) for the Asian population. Wan et al (39) performed a risk estimate with various tumor types. The OR for uterine cancer (eight studies) revealed an increased risk for GG vs. TT (OR, 1.34; 95\% CI, 1.07-1.69) and (OR, 1.36; 95\%CI, 1.18-1.56) for the Asian population (32 studies). This study included six studies (two for breast cancer, and one each for acute myeloid leukemia, hepatocellular carcinoma, lung cancer and gastric cancer) that explored interaction effects between TP53 Arg72Pro and MDM2 SNP309. They found that the combination of GG and Pro/Pro, TG and Pro/Pro and GG and Arg/Arg in comparison to the reference MDM2 SNP309 TT and TP53Arg/Arg genotype, significantly increased the risk of cancer (OR, 3.38; 95\% CI, 1.77-6.47), (OR, 1.88; 95\% CI, 1.26-2.81) and (OR, 1.96; 95\% CI, 1.01-3.78), respectively. Wo et al (40) completed a meta-analysis with multiple types of tumors, including four endometrial cancer studies. The OR reflected an increased risk of cancer for GG vs. TT (OR, 1.123; 95\% CI, 1.056-1.193). Li et al (41) conducted a meta-analysis of 1,001 cases and 1,889 controls from six published case-control studies $(24-26,33,35)$ to estimate the effect of SNP309 on endometrial cancer risk for GG vs. TT (OR, 1.54; 95\% CI, 1.21-1.95). These analyses indicate that MDM2 SNP309 serves as a tumor susceptibility marker, and that there is an association between MDM2 SNP309 and TP53 Arg/Pro regarding tumor susceptibility.

The other notable finding of the present study was that the combination of the TP53 72Pro allele and homozygosity for the $p 21$ codon 31 Ser allele was associated with a decreased risk of endometrial cancer. This is in contrast to a previous study showing that the combination of the TP53 Pro allele and p21 Ser/Ser genotype significantly increased endometrial cancer risk (OR, 9.55; 95\% CI, 4.40-21.24) (22). The result requires further investigation.

Finally, we investigated whether the SNP309 subtype modified the effect of RITA, an agent that blocks the p53-MDM2 interaction. RITA suppresses the proliferation of endometrial cancer cell lines. The effect was less pronounced in HHUA and Sawano cells containing the SNP309 G allele compared with that in Hec6 cells, which harbor the TT genotype. Arva et al (42) showed that cells carrying the SNP309 GG genotype exhibited a compromised TP53 response pathway and formed transcriptionally inactive p53-MDM2 complexes in response to stress. These results support our findings. Additional functional analyses are required to fully elucidate the effects of these polymorphisms on the effect of agents such as RITA on endometrial cancer cell lines.

In conclusion, endometrial cancer is characterized by numerous genetic alterations, including those in p53, K-ras, PTEN and $\beta$-catenin. We previously demonstrated that the Ras/ER/MDM2 pathway is important for proliferation of endometrial cancer cells in vitro. We demonstrated in this case-control study that polymorphisms of TP53 and MDM2 modify the effect of this signaling pathway and thus increase the risk of endometrial cancer.

The increased incidence of endometrial cancer in Japan may reflect changes in lifestyle. The interplay between genetic and environmental factors is now being investigated in the context of gynecologic cancer. It is well known that endometrial cancer risk includes an environmental component. Further studies are necessary to elucidate the genetic components of risk. Understanding this relationship is the first step towards developing new methods of endometrial cancer prevention and treatment.

\section{Acknowledgements}

The authors acknowledge the generous support of Professor Suminori Kono (Preventive Medicine, School of Medicine, Kyushu University) for conducting the survey of controls and for valuable discussion. We are grateful to Drs Masao Okadome, Takako Eto, Kazuya Ariyoshi, Tomoko Hagiwara, Shintaro Yanadume, Masahumi Yasunaga, Hiroko Imamura, Ryosuke Tsunematsu and Kenzo Sonoda for their help in the survey of cases. We appreciate the technical support provided by the Research Support Center, Graduate School of Medical Sciences, Kyushu University. This study was supported by a grant-in-aid for Cancer Research (17-9) from the Ministry of Health, Labour and Welfare, Japan.

\section{References}

1. Bansal N, Yendluri V and Wenham RM: The molecular biology of endometrial cancers and the implications for pathogenesis, classification, and targeted therapies. Cancer Control 16: 8-13, 2009.

2. Prat J, Gallardo A, Cuatrecasas M and Catasus L: Endometrial carcinoma: pathology and genetics. Pathology 39: 72-87, 2007.

3. Deb SP: Cell cycle regulatory functions of the human oncoprotein MDM2. Mol Cancer Res 1: 1009-1016, 2003.

4. Haupt Y, Maya R, Kazaz A and Oren M: Mdm2 promotes the rapid degradation of p53. Nature 387: 296-299, 1997. 
5. Honda R, Tanaka $\mathrm{H}$ and Yasuda $\mathrm{H}$ : Oncoprotein MDM2 is a ubiquitin ligase E3 for tumor suppressor p53. FEBS Lett 420: 25-27, 1997.

6. Kubbutat MH, Jones SN and Vousden KH: Regulation of p53 stability by Mdm2. Nature 387: 299-303, 1997.

7. Levav-Cohen Y,Haupt S and Haupt Y: Mdm2 in growth signaling and cancer. Growth Factors 23: 183-192, 2005.

8. Gudas JM, Nguyen H, Klein RC, Katayose D, Seth P and Cowan KH: Differential expression of multiple MDM2 messenger RNAs and proteins in normal and tumorigenic breast epithelial cells. Clin Cancer Res 1: 71-80, 1995.

9. Sheikh MS, Shao ZM, Hussain A and Fontana JA: The p53-binding protein MDM2 gene is differentially expressed in human breast carcinoma. Cancer Res 53: 3226-3228, 1993.

10. Ries S, Biederer C, Woods D, et al: Opposing effects of Ras on p53: transcriptional activation of $\mathrm{mdm} 2$ and induction of p19ARF. Cell 103: 321-330, 2000.

11. Kato K, Ueoka Y, Hachiya T, Nishida J and Wake N: Contribution of enhanced transcriptional activation by ER to [12Val] K-Ras mediated NIH3T3 cell transformation. Oncogene 15: 3037-3046, 1997.

12. Kato K, Horiuchi S, Takahashi A, et al: Contribution of estrogen receptor $\alpha$ to oncogenic K-Ras-mediated NIH3T3 cell transformation and its implication for escape from senescence by modulating the p53 pathway. J Biol Chem 277: 11217-11224, 2002.

13. Suga S, Kato K, Ohgami T, et al: An inhibitory effect on cell proliferation by blockage of the MAPK/estrogen receptor/ MDM2 signal pathway in gynecologic cancer. Gynecol Oncol 105: 341-350, 2007.

14. Bond GL, Hu W, Bond EE, et al: A single nucleotide polymorphism in the MDM2 promoter attenuates the p53 tumor suppressor pathway and accelerates tumor formation in humans. Cell 119: 591-602, 2004.

15. Bond GL, Hirshfield KM, Kirchhoff T, et al: MDM2 SNP309 accelerates tumor formation in a gender-specific and hormonedependent manner. Cancer Res 66: 5104-5110, 2006

16. Campbell IG, Eccles DM and Choong DY: No association of the MDM2 SNP309 polymorphism with risk of breast or ovarian cancer. Cancer Lett 240: 195-197, 2006.

17. Petenkaya A, Bozkurt B, Akilli-Ozturk O, Kaya HS, Gur-Dedeoglu B and Yulug IG: Lack of association between the MDM2-SNP309 polymorphism and breast cancer risk. Anticancer Res 26: 4975-4977, 2006.

18. Krekac D, Brozkova K, Knoflickova D, et al: MDM2SNP309 does not associate with elevated MDM2 protein expression or breast cancer risk. Oncology 74: 84-87, 2008.

19. Vogelstein B, Lane D and Levine AJ: Surfing the p53 network. Nature 408: 307-310, 2000

20. el-Deiry WS, Tokino T, Velculescu VE, et al: WAF1, a potential mediator of p53 tumor suppression. Cell 75: 817-825, 1993.

21. Roh J, Kim M, Kim J, et al: Polymorphisms in codon 31 of p21 and cervical cancer susceptibility in Korean women. Cancer Let 165: 59-62, 2001.

22. Roh JW, Kim JW, Park NH, et al: p53 and p21 genetic polymorphisms and susceptibility to endometrial cancer. Gynecol Oncol 93: 499-505, 2004

23. Hachiya T, Kuriaki Y, Ueoka Y, Nishida J, Kato K and Wake N: WAF1 genotype and endometrial cancer susceptibility. Gynecol Oncol 72: 187-192, 1999.

24. Walsh CS, Miller CW, Karlan BY and Koeffler HP: Association between a functional single nucleotide polymorphism in the MDM2 gene and sporadic endometrial cancer risk. Gynecol Oncol 104: 660-664, 2007.
25. Terry K, McGrath M, Lee IM, Buring J and De Vivo I: MDM2 SNP309 is associated with endometrial cancer risk. Cancer Epidemiol Biomarkers Prev 17: 983-986, 2008.

26. Ueda M, Yamamoto M, Nunobiki O, et al: Murine double-minute 2 homolog single nucleotide polymorphism 309 and the risk of gynecologic cancer. Hum Cell 22: 49-54, 2009.

27. Ueda M, Terai $Y$, Kanda K, et al: Germline polymorphism of $\mathrm{p} 53$ codon 72 in gynecological cancer. Gynecol Oncol 100: 173-178, 2006.

28. Yaich L, Dupont WD, Cavener DR and Parl FF: Analysis of the $P v u$ II restriction fragment-length polymorphism and exon structure of the estrogen receptor gene in breast cancer and peripheral blood. Cancer Res 52: 77-83, 1992.

29. Mizunuma H, Hosoi T, Okano H, et al: Estrogen receptor gene polymorphism and bone mineral density at the lumbar spine of pre- and postmenopausal women. Bone 21: 379-383, 1997.

30. Sun Y, Hildesheim A, Li H, et al: No point mutation but a codon 31ser $\rightarrow$ arg polymorphism of the WAF-1/CIP-1/p21 tumor suppressor gene in nasopharyngeal carcinoma (NPC): the polymorphism distinguishes Caucasians from Chinese. Cancer Epidemiol Biomarkers Prev 4: 261-267, 1995.

31. Shih CM, Lin PT, Wang HC, Huang WC and Wang YC: Lack of evidence of association of p21WAF1/CIP1 polymorphism with lung cancer susceptibility and prognosis in Taiwan. Jpn J Cancer Res 91: 9-15, 2000.

32. Issaeva N, Bozko P, Enge M, et al: Small molecule RITA binds to $\mathrm{p} 53$, blocks $\mathrm{p} 53-\mathrm{HDM}-2$ interaction and activates $\mathrm{p} 53$ function in tumors. Nat Med 10: 1321-1328, 2004.

33. Ashton KA, Proietto A, Otton G, et al: Polymorphisms in TP53 and MDM2 combined are associated with high grade endometrial cancer. Gynecol Oncol 113: 109-114, 2009.

34. Niwa Y, Hirose K, Matsuo K, et al: Association of p73 G4C14-to-A4T14 polymorphism at exon 2 and p53 Arg72Pro polymorphism with the risk of endometrial cancer in Japanese subjects. Cancer Lett 219: 183-190, 2005.

35. Nunobiki O, Ueda M, Yamamoto M, et al: Polymorphisms of p53 codon 72 and MDM2 promoter 309 and the risk of endometrial cancer. Hum Cell 22: 101-106, 2009.

36. Enomoto T, Fujita M, Inoue M, et al: Alterations of the p53 tumor suppressor gene and its association with activation of the c-K-ras-2 protooncogene in premalignant and malignant lesions of the human uterine endometrium. Cancer Res 53: 1883-1888, 1993.

37. Wilkening S, Bermejo JL and Hemminki K: MDM2 SNP309 and cancer risk: a combined analysis. Carcinogenesis 28: 2262-2267, 2007.

38. Hu Z, Jin G, Wang L, Chen F, Wang X and Shen H: MDM2 promoter polymorphism SNP309 contributes to tumor susceptibility: evidence from 21 case-control studies. Cancer Epidemiol Biomarkers Prev 16: 2717-2723, 2007.

39. Wan Y, Wu W, Yin Z, Guan P and Zhou B: MDM2 SNP309, gene-gene interaction, and tumor susceptibility: an updated meta-analysis. BMC Cancer 11: 208, 2011.

40. Wo X, Han D, Sun H, et al: MDM2 SNP309 contributes to tumor susceptibility: a meta-analysis. J Genet Genomics 38: 341-350, 2011.

41. Li Y, Zhao H, Sun L, Huang L, Yang Q and Kong B: MDM2 SNP309 is associated with endometrial cancer susceptibility: a meta-analysis. Hum Cell 24: 57-64, 2011.

42. Arva NC, Gopen TR, Talbott KE, et al: A chromatin-associated and transcriptionally inactive p53-Mdm2 complex occurs in mdm2 SNP309 homozygous cells. J Biol Chem 280: 26776-26787, 2005. 